\title{
Involvement of small and medium-sized enterprises (SMEs) in elaborating and implementing public policies: Study case- Romanian small and medium-sized enterprises
}

\author{
RuXandra POPESCU \\ The Bucharest University of Economic Studies, Bucharest, Romania \\ ruxandra.popescu@rei.ase.ro \\ Stefania GHIOCANU \\ University of Bucharest, Bucharest, Romania
}

\begin{abstract}
Involvement and development of the private sector in boosting the economy nationwide is a main objective of the current program of the government, which means that a good cooperation between small and medium companies, private companies and multinationals and public environment including both public institutions and policies implemented and developed by them, becomes more than necessary. The paper summarizes the findings of a quantitative research based on a self-applied questionnaire which was aimed at Romanian small and medium-sized enterprises and also of a qualitative research that gives an overview of the process of elaborating and implementing a public policy. The involvement of small and medium-sized enterprises in the process of designing and implementing a public policy can become indispensable but it is well know that there is, in fact, a lack of initiative at this level, from both parties. One of the main research questions of this paper is to find out how much do representatives of small and medium-sized enterprises get involved in the process of elaborating a public policy and how much do these actions and measures impact the organizational policies of the companies themselves. A good cooperation between the business environment and the public institutions and a strong correlation of their joint efforts, should become a common practice between both parties, being crucial that this form of cooperation to be initiated from the very beginning. The contribution of this paper is a practical one, given the fact that the paper itself entails the direct responses of small and medium-sized enterprises on the current and future public policies that directly targets them, providing as well an analysis on the effects of public policies on small and medium-sized enterprises. Thus being said, the paper can also be a guide for both small and medium-sized enterprises in providing examples and measures of involvement and favorable public policies development, but also for public institutions by analyzing responses based on practice activities of small and mediumsized enterprises; giving them a solution to correct or continue generating positive results of those policies.
\end{abstract}

Keywords: Small medium-sized enterprises, public policies, practices.

\section{Introduction}

In order to correctly identify and assess a specific problem within the society, a thorough analysis of the situation with the direct involvement of the most relevant actors, becomes indispensable and much needed in order to have a public policy that responds specifically to the identified need. As a result, in order to have a public policy that offers a concrete solution for the business environment, SMEs should have an imposing and decisive role in 
the process of elaborating and implementing a public policy which would have a direct impact on them. Unfortunately, as the paper examines the current state of Romanian SMEs involvement in the process elaborating and implementing of public policies, the majority of the results lead to the conclusion that often best practices taken from theory do not always fully apply in practice.

\section{Literature review}

Many researchers have attempted to define the concept of public policy and its process of elaboration and implementation. In order to fully understand how a public policy works, an increased attention should be paid to the core objectives and goals of the public policy itself and its drivers (Anderson J. E., 2003). Public policies are formulated in order to obtain several objectives, which usually can be found within the programs of the government. These goals and objectives are the result of an extensive process of identifying a specific problem within the society and of finding ways and solutions of responding to it (Charles L. Cochran \& Eloise F. Malone, 2014). Therefore, a public policy becomes an essential instrument/strategy to achieve the desired objectives through concrete actions supported by a close relation and cooperation between various bodies and agencies. Murray (1998) claimed that the involvement of SMEs in public policies that have their own development as an objective should be an opportunity not only for SMEs but also for their authors, thus easing the decision making and implementation process and also of the evaluation process of results. Along these lines, it has been affirmed the fact that public policies, even if they are implemented to help an initial target group, does not mean by default that they just have to wait for the results, being that the recommendations of public actors on existing problems, their severity or offering solutions may not be as real as those identified within the direct target group (Gibb A.A., 2000).

\section{The importance of involving SMEs in the elaboration and implementation of public policies}

It's well know that only certain key actors are those who have direct responsibilities in the process of elaborating and implementing a public policy. Most often these actors are national public institutions, central or local NGOs and other government structures. In this relationship, the SMEs can be defined as direct beneficiaries of a certain public policy, having no specific responsibilities regarding the elaboration and implementation process. That being said, SMEs do have the opportunity to intervene and to influence the process (Zulean, Miroiu \& Radoi, 2002).

Direct beneficiaries of a policy are allowed, even recommended, to decide on a public policy that affects them in order to identify the real problems they usually face and also specific causes, in order to propose actions to be put into place, proposals methods and also collaborations with other institutions working in the field. They also can occur even after the policy was implemented but had no impact, requiring in this case an amendment. Why is that important to involve SMEs in the elaboration and implementation of public policies that targets them directly? Consultations with representatives from different SMEs, offering therefore the opportunity for an active involvement in the entire process, could lead to the following results: identifying real issues resulted from the SMEs experience and practice, ensuring transparency for the implementation process of policies, increasing the 
cooperation with public institutions and last but not least, increasing the confidence of SMEs in public institutions, which could lead in time to an increase in investments and development opportunities of new SMEs. In short, the benefits of involving SMEs in the process of elaborating and implementing public policies are represented in the diagram below:

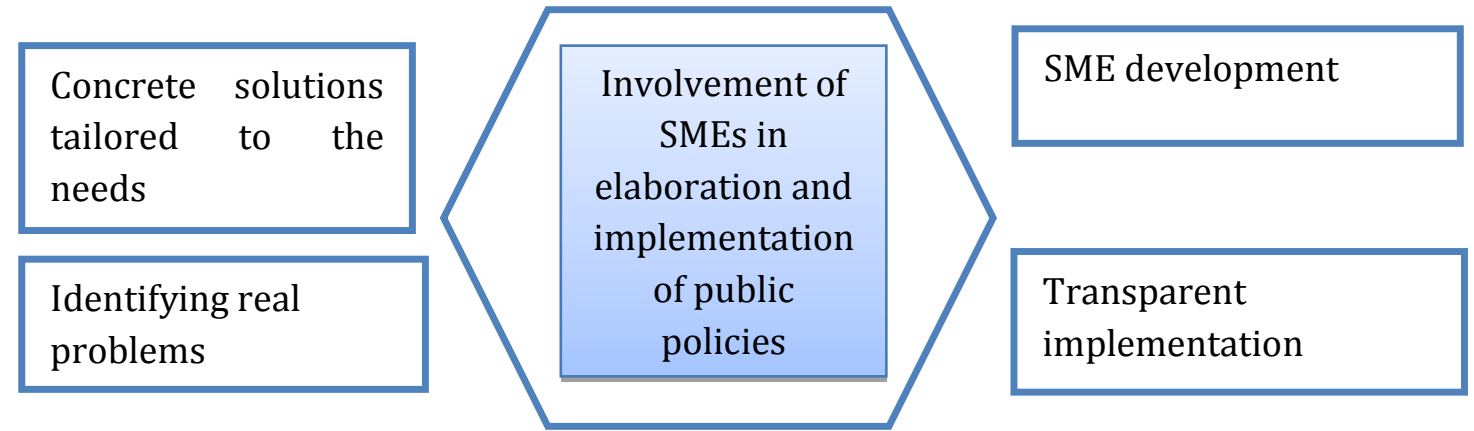

PICBE $\mid 552$

Figure 1, Benefits of involvement of SMEs in elaboration and implementation of public policies

Source: Authors' own contribution.

As there are several benefits of involving SMEs in elaborating and implementing public policies, there could be also identified several disadvantages, mentioning that the advantages surely overcome the disadvantages, due to a much greater importance. Some of the disadvantages may include: (1) Failure agreements between SMEs on existing problems (2) A large number of SMEs that want to be involved in the entire process, which could lead to slowing down the entire process and even requiring additional resources (3) Lack of actual experience of SME representatives in the field which could lead to unsustainable solutions. Despite these drawbacks, we firmly believe that the involvement of SMEs has a long term social and economic impact and a higher chance that all the resources that are being used during this process, could be fully recovered later. Also, their involvement would not only mean a boost in their development and hence an increase in employability, which could lead to the result of having a double positive effects nationwide: a drop in unemployment among both youth and adults and an increased economic growth. Thus, we dare to say that the involvement of SMEs in the process of implementing public policies brings benefits for SMEs but also for public institutions and the country as a whole.

\section{Recent changes in the field}

When analyzing the importance of the actual involvement of Romanian SMEs in elaborating and implementing public policies, it becomes necessary to give a general overview over the most important legislative projects that have been adopted in the field, in Romania. Among the most recent legislative project that has the role to support the work and development of SMEs includes the "Start-up Nation - Romania", a program adopted on $1 / 27 / 2017$, by Ordinance no.10/2017 that has the overall objective of stimulating the establishment of new SMEs(http://www.immromania.ro). It aims to encourage entrepreneurship by providing one of the following important regulations: support up to 44,000 EUR per beneficiary for an estimated number of 10,000 small and medium enterprises (it is estimated that this measure will create at least 20,000 new jobs annually). The program beneficiaries are SMEs established after the entry into force of the ordinance. Another legislative change that targets the SME development in agriculture, offers farmers the 
necessary support through a government program to cultivate tomatoes in specially protected areas (greenhouses, solariums). Through these measures, the government has taken into consideration not only economic growth and development of SMEs in this field but also an increased employability especially among young people, the action taken on the development of SMEs. Also, another important document that can benefit SMEs is the SME Strategy 2020 which aims at increasing the development of companies with more than $40 \%$ for the following European financial year. It's important to mention that the main priorities on the government program for SMEs for the period 2013-2016 were the following: (1) improving the existing regulatory framework; (2) promoting vocational education and entrepreneurial culture; (3) creation of new jobs; (4) improving SME access to funding; (5) Stimulating research, development and innovation; (6) encouraging public-private partnership. The following objectives were proposed as part of several public policies that targeted SME development: (1) A strategic vision on rural development, (2) Development of administrative capacity for monitoring and evaluating measures adopted by the government; (2) A better regulatory framework to facilitate compliance by all operators for the existing legislation; (3) The promotion of quality education focused on the power to provide the skills required by the labor market and society (4) Developing partnerships between public and private sectors, including local governments and research institutions. The overall objective is to create a favorable environment for business, private initiative and entrepreneurship, to foster the creation and development of SMEs and to improve business competitiveness at local, regional, national, European and international level.

\section{Data analysis and findings}

In order to assess the level of involvement of SMEs in the process of designing and implementing a public policy, a questionnaire was applied to Romanian SMEs representatives. The survey ream chose only respondents that fit in the category of Romanian SMEs from a wide variety of fields. Out of 180 SMEs approached, 50 completed the questionnaires, having an overall response rate of $28 \%$. The questionnaire included a number of 23 opened and closed questions and had the goal to gather quantitative and qualitative data on the SMEs activities in the process of elaborating a public policy. Out of 50 questionnaires only 40 were completed correctly and accordingly to instructions. In order to obtain answers to the initial research hypothesis, the questionnaire was designed to respond to several successive questions such as (1) If and how are the activities implemented by SMEs influenced by legislative changes in the area (2) If and how do SMEs get involved in the process of designing and implementing public policies (3) How effective is the relationship between public authorities and SMEs in elaborating and implementing public policies. The purpose of gathering initial questions (see Table 1) in regard to the respondents is to give an overview of the experience of the SME and also of the actual representative of the SME that acted as a respondent. It's important to mention that over $78 \%$ of the respondents have a high level position within the SME and over $45.5 \%$ of the SME have an experience of over 10 years. These results could show us that a majority of the collected answers are based on practical experience.

Table 1, Results of the questionnaire

\section{Question 1: Position of the respondent within the} SME 


\begin{tabular}{|c|c|}
\hline Response & Percent rate \\
\hline High level position & $78 \%$ \\
\hline Middle level position & $18 \%$ \\
\hline Low level position & $4 \%$ \\
\hline \multicolumn{2}{|c|}{ Question 2: For how long is the SME active? } \\
\hline Response & Percent rate \\
\hline 0 to 5 years & $18.2 \%$ \\
\hline 5 to 7 years & $21.2 \%$ \\
\hline 7 to 10 years & $15.2 \%$ \\
\hline Over 10 years & $45.5 \%$ \\
\hline \multicolumn{2}{|c|}{ Question 3: How was founded the SME? } \\
\hline Response & Percent rate \\
\hline Own funds & $84.8 \%$ \\
\hline Public funds & $9.1 \%$ \\
\hline Foreign Investments & $24.2 \%$ \\
\hline International funds & $3 \%$ \\
\hline Others & $0 \%$ \\
\hline
\end{tabular}

PICBE $\mid 554$

In analyzing the impact of what it's actually thought to have on the day to day activities of SMEs, over $84.8 \%$ of the respondents have agreed affirmatively that their activity is directly influenced by legislative changes in the area, whilst $12.1 \%$ responded that it depends on the nature of the legislative changes, remaining with three percent that do now agree with any kind of impact of any sort of legislative changes. When asked to evaluate the modality in which their activity is influenced by legislative changes, a strong part of the respondents have answered that usually the legislative changes have a negative impact on their businesses. The purpose of finding out the opinion of the respondents in regard to what sort of influence do some certain legislative changes have, is to correlate these results with the actual involvement of SMEs in the process of designing and elaborating a public policy. The first step was to find out how many of the respondents have been involved in any activities of elaborating and implementing a public policy, 69.6\% of them admitting that they did not get involved in any step of the process, whilst just $18.2 \%$ have fully confirmed their involvement, $12.1 \%$ admitting that they occasionally participated in such sort of activities.

As important as the last data, the next open question had the purpose of gathering information on the modalities and levers that have been used by the respondents in order to get involved in the process of elaborating and implementing a public policy. Amongst the means listed as a result of the question, the majority of the respondents answered that they have used modalities such as complaints and protests and only a few of the respondents mentioned participation in public debates, conferences, seminars and written recommendations on certain open documents for debate. When asked if the SME has acted in a proactive way, along with other SMEs, in a situation where any kind of legislative change or adoption of public policies has produced negative or unsatisfactory effects, over $50 \%$ of the respondents have answered that they did not take any action as a result, arguing that they don't have the necessary means and resources to act upon it and even if they act, their actions are not taken into consideration. In correlation with the last question, over 
$69.7 \%$ of the respondents have affirmed that they are part of a SME group or association whilst 30. 3\% have declared that are not part of any association of such sort. The questionnaire's third objective was to find out how effective is the relationship between public authorities and SMEs in elaborating and implementing public policies and how high or low is the level of trust between these two key actors. When asked if Romania, through its public authorities, has undertaken measures to promote a good collaboration between institutions and SMEs, over $66.7 \%$ have answered that there isn't any kind of collaboration between them and the public actors, whilst just three percent fully agreed that they have in fact a good cooperation (three of the respondents answered sometimes while 27.3\% responded not always). Taking into consideration the correlation made between different types of questions, the questionnaire had also the purpose to collect valuable recommendations and proposed changes directly from the SMEs, in order to have a better collaboration with the public authorities. Among the answers given, some of the most often answers were: reduced bureaucracy, establishing an efficient system/platform that could allow a constant and open cooperation between private and public environment, fully respected legal procedures from both sides, development of projects/partnerships that involve both parties, a raised support for the development of SMEs, simplification of different procedures that involve the activity of SMEs, digitization and open communication across all channels, high transparency in regards to all activities involving SMEs and also an extended period of consultations between public authorities and SMEs. Having in mind the interpretation of the questionnaires, we find it important to mention that the objectives of the 2020 Strategy on measures supporting SMEs, which should have been fulfilled until 2016, were not successfully reached. The measures that should have been fulfilled and that can be found as well as part of proposals within our own questionnaire are the following: Measure 5: An online platform created for guidance and advice regarding European programs and tools specifically dedicated to startups and SMEs, Measure 6: Promoting ethical behavior in business and supporting honest entrepreneurs who want to start a business such public events on business ethics - deadline 2015, Measure 8: platform for startups and SMEs -deadline 2016, Measure 25: Stimulating the formation and development of business networks deadline 2014-2015.

\section{Recommendations and conclusions}

The need of involving different yet relevant actors in the process of elaboration and implementation of public policies has become more than necessary. Public authorities should have the purpose of identifying real problems found in society, in a strong collaboration with other important and relevant actors. These type of actors could give invaluable input in both identifying the problem but also in offering solutions that respond directly to that certain issue. Whilst analyzing the efforts made by Romanian public authorities to involve different stakeholders in this process of elaboration and implementation, the questionnaire's results show that in reality SMEs either do not know exactly how they could get involved in such a process or in case they are aware of the instruments they have, they take the decision of not using it, admitting that they do not think that their actions and input will be taken into consideration. From the analyze that has been done on the current situation in Romania and in order to increase the active involvement of SMEs in the process of elaboration and implementation of public policies, we propose the following recommendations: (1) A better promotion of modalities in which 
certain different actors can get involve in the process of elaborating and implementing a public policy. This recommendation comes as a result of different answers from respondents that revealed that a significant number of them did not know in fact that they can have an active role in the process nor the type of instruments they can use. (2) A higher involvement of SMEs in the process of elaborating the public policies, through a number of open debates, spread on a longer period of time, in order to assure that all interested participants have presented their point of view (3) Establishing a platform/online instrument which could encourage communication at all stages of the process (4) Maintaining a good communication and cooperation between parties even after the public policy has been adopted in order to assess if the results are the ones expected and implement corrective measures if necessary. Once again this recommendation comes as a result of our research, having situations when some envisaged actions and measures do not produce the desired results. In these particular cases, a permanent evaluation, in cooperation with SMEs becomes necessary.

\section{References}

Anderson, J. E. (2003). Public policymaking: An introduction, Boston: Houghton Mifflin Company, pp. $1-34$.

Cochran, L.C., Malone, F.E. (2014). Public Policy: Perspectives and Choices, Lynne Rienner Publisher.

Murray G.C. (1998), A policy response to Regional Disparities in the Supply of Risk Capital to New Technology-based Firm in EU", Regional Studies, 32 (5), 410.

Gibb A.A. (2000). SME Policy, Academic Research and the Growth of Ignorance, Mythical Concepts, Myths, Assumptions, Rituals and Confusions, International Small Business Journal 18(3), 11.

Zulean M., Miroiu A., Radoi M. (2002), Analiza politicilor publice, Punct.

Intreprinderi Mici si Mijlocii Romania (2017), Sprijin financiar pentru producatorii de tomate. Retrieved from http://www.immromania.ro/sprijin-financiar-pentruproducatorii-de-tomate-8946.htm. 